\title{
Research
}

\section{What we talk about when we talk about depression:}

\author{
doctor-patient conversations and treatment decision outcomes
}

\begin{abstract}
Background

Efforts to address depression in primary care settings have focused on the introduction of care guidelines emphasising pharmacological treatment. To date, physician adherence remains low. Little is known of the types of information exchange or other negotiations in doctor-patient consultations about depression that influence physician decision making about treatment.
\end{abstract}

\section{Aim}

The study sought to understand conversational influences on physician decision making about treatment for depression.

\section{Design}

A secondary analysis of consultation data collected in other studies. Using a maximum variation sampling strategy, 30 transcripts of primary care consultations about distress or depression were selected from datasets collected in three countries. Transcripts were analysed to discover factors associated with prescription of medication.

\section{Method}

The study employed two qualitative analysis strategies: a micro-analysis approach, which examines how conversation partners shape the dialogue towards pragmatic goals; and a narrative analysis approach of the problem presentation.

\section{Results}

Patients communicated their conceptual representations of distress at the outset of each consultation. Concepts of depression were communicated through the narrative form of the problem presentation. Three types of narratives were identified: those emphasising symptoms, those emphasising life situations, and mixed narratives. Physician decision making regarding medication treatment was strongly associated with the form of the patient's narrative. Physicians made few efforts to persuade patients to accept biomedical attributions or treatments.

\section{Conclusion}

Results of the study provide insight into why adherence to depression guidelines remains low. Data indicate that patient agendas drive the 'action' in consultations about depression. Physicians appear to be guided by common-sense decision-making algorithms emphasising patients' views and preferences.

\section{Keywords}

conceptual models; decision making; depression; discourse analysis; doctor-patient relations; narrative analysis; illness representation.

\section{INTRODUCTION}

Current guidelines for primary care depression treatment in Europe and the US, reflect a biomedical model of the disorder. According to the biomedical model, depression is conceptualised as a matter of individual pathology resulting from dysfunction and disrepair at the level of brain, personality, or cognition. ${ }^{1-4}$ While they may differ in minor details, the guidelines are broadly similar. Most share a similar emphasis on accurate diagnosis and the provision of technical treatments specifically, antidepressant prescription and mental health referral.5,6 Although most primary care physicians are familiar with the guidelines, ${ }^{7-9}$ overall physician adherence is poor.

Although the depression guidelines seem uncomplicated, it has been suggested that their very simplicity is at odds with the reallife complexities of treating psychological distress in primary care settings. $3,10-13$ According to the guidelines, the decision of whether to prescribe a technical treatment is based largely on diagnosis: cases that meet criteria for moderate or severe depression should be treated with medication and/or psychotherapy. The patient's concept of his or her condition

A Karasz, PhD, associate professor, L Ferri, MA psychologist, World Trade Center Environmental Health Center, Bellevue Hospital, New York, NY

US. C Dowrick, MD, FRCGP, professor of primary medical care; J Reeve, PhD, MRCGP, NIHR clinician scientist in primary care, mental and behavioural health sciences, University of Liverpool, Liverpool. R Byng, PhD, MRCGP. clinical senior lecturer, Peninsula Medical School, University of Plymouth, Plymouth. M Buszewicz, MRCGP, MRCPsych, senior lecturer in primary care, Research Department of Primary Care and Population Health, University College, London. TC Olde Hartman, MD, PhD, GP; E Van WeelBaumgarten, PhD, MD, associate professor,

Department of Primary and Community Care Radboud University Nijmegen Medical Centre, Nijmegen, the Netherlands. S van Dulmen, PhD, does not play an explicit role in the physician's decision to offer treatment. ${ }^{14}$ Yet patients' beliefs, attitudes, and preferences about depressive symptoms will play an important role in any doctor-patient consultation in which the physician seeks to provide patient-centred care.

Providing patient-centred care may conflict with the decision algorithms provided in the guidelines for depression treatment. Many primary care patients do not share the basic premises of the biomedical model of depression,11,15 regarding depression not as a disease, but as the outcome of social problems. ${ }^{16}$ As a consequence, such patients are unwilling to accept the biomedical treatment indicated in the guidelines. Physicians, similarly, may doubt the relevance of the biomedical model in some cases. Data suggest that physicians are reluctant to prescribe antidepressants to patients with symptoms that seem attributable to life problems and difficulties.8,13,17 In such cases, physicians may base their treatment decisions on informal algorithms derived from common sense or clinical experience. ${ }^{18}$ Since the conversations between doctors and patients about depression have been little investigated,

research coordinator, Communications in Healthcare, Netherlands Institute for Health Services Research, Utrecht, the Netherlands.

\section{Address for correspondence}

Alison Karasz, Department of Family and Social Medicine, Albert Einstein College of Medicine, Mazer 411, 1300 Morris Park Boulevard, Bronx, New York 10461, USA.

E-mail: alison.karaszdeinstein.yu.edu Submitted: 1 April 2011; Editor's response: 18 May 2011; final acceptance: 25 July 2011 (CBritish Journal of General Practice This is the full-length article lpublished online 27 Dec 2011) of an abridged version published in print. Cite this article as: Br J Gen Pract 2011; DOI: 10.3399/bjgp12X616373 


\section{How this fits in}

Concordance with depression guidelines and rates of pharmacological treatment for primary care depression remain low.

Evidence suggests that both patients and doctors may view depression that is linked to social causes as unlikely to benefit from pharmacological treatment. This study is the first to examine how doctors and patients communicate regarding the nature, social or biological, of the depression problem. Results suggest physicians are highly responsive to patients' cues in this regard. Physicians appear to anticipate patient preferences, and rarely offer medication for depression that is presented in social terms. Physician behaviour in the present analysis was consistent with principles of patient-centred care. It may be that the emphasis on technical treatments implied by the guidelines is inconsistent with a patient-centred approach to depression care.

very little is known of the kinds of interactions and informational exchange during the consultation that may influence physician decision making in this regard.

The present study examined doctor-patient consultations about psychological distress to understand how patients and doctors make decisions about depression treatment. Interactional data can generate important insights into primary care processes and outcomes, addressing the limitations of self-report methods. ${ }^{19}$ A few previous studies have examined doctor-patient discourse in depression or distress. Most use a process analysis' approach, which classifies discourse into broad functional categories such as 'psychosocial disclosure' or 'patient requests', and examines the frequencies of these categories in relation to diagnostic or treatment decision outcomes. ${ }^{20-22}$ These studies have yielded important results. Yet they provide relatively little insight into the interactional processes that shape the outcomes of conversations about distress and depression. ${ }^{23}$

The present study, by contrast, used a 'micro-analysis' approach. This analytic strategy focuses on interactional sequences between conversation partners. It is based on the assumption that conversation partners actively shape conversations through patterns of mutual elicitation and response - to achieve specific pragmatic or social goals. ${ }^{24}$ The study explored how interaction patterns common to most doctor-patient conversations - including the problem presentation, the solicitation of information, and the formulation of the problem - shaped physician decision outcomes in the management of distress.

\section{METHOD}

\section{Sample}

In selecting a sample of consultations for the present study, the investigators used a type of purposive sampling called maximum variation sampling. ${ }^{25}$ In this approach, the goal of sample selection is to maximise the variability of the sample by including a broad range of cases from varied settings. Maximum variation sampling is appropriate when little is known of the contextual variables likely to influence the outcomes of interest. If similar results arise across a broad range of cases, this is said to strengthen the inferences that may be drawn from results. ${ }^{25}$

In keeping with this strategy, consultation transcripts were selected for this analysis from four diverse datasets of consultations about psychological distress that had been collected in previous studies. Two of these datasets were from the UK, one from the Netherlands, and one from the US. The datasets had been collected to address different research questions and differed from one another in important respects (see Appendix 1 for a detailed description of the datasets.) In the first phase of sample selection, consultations were selected that included a conversation between doctor and patient about the patient's psychological distress.

In a second step, 30 consultations were selected from the four datasets. Because the goal of the study was to explore how interactional patterns might be associated with physician behaviours, the consultations chosen were characterised by three key physician behaviours: the offer of medication, the offer of psychotherapy referral, and no offer of formal treatment. At least 10 consultations with each outcome were selected.

The present analysis focuses on consultation processes associated with medication prescription. In other words, consultations that included an offer of medication were compared to those that did not.

\section{Procedure}

The study took a micro-analytic approach to the analysis. This approach to understanding dyadic verbal interaction is based on the premise that conversation is functional and goal oriented. According to this perspective, conversational partners 


\begin{tabular}{|c|c|}
\hline \multicolumn{2}{|l|}{ Characteristic } \\
\hline \multicolumn{2}{|l|}{ Nationality, $n$} \\
\hline US & 12 \\
\hline UK & 10 \\
\hline Netherlands & 8 \\
\hline Patient sex, females & 16 \\
\hline Patient age, mean (range), years & $\begin{array}{c}39.8 \\
(19-84)\end{array}$ \\
\hline \multicolumn{2}{|l|}{ Patient ethnicity, \% } \\
\hline White & 70 \\
\hline Black & 5 \\
\hline Hispanic & 18 \\
\hline Other & 3 \\
\hline Physician offers antidepressant, $n$ & 16 \\
\hline Accepted & 10 \\
\hline Patient requests medication, $n$ & 3 \\
\hline
\end{tabular}

actively shape conversations in order to achieve specific pragmatic or social goals. ${ }^{24}$ In the analysis, the study sought to understand doctors' and patients' goals for their conversation about depression and the strategies they used to achieve their goals. How did patients describe their depressive symptoms? What sorts of information did physicians elicit? How did patients and physicians negotiate decisions about treatment? How did the dyad manage disagreement?

A coding scheme derived from previous work of the authors and others was developed for the analysis. ${ }^{23,26}$ The scheme identifies conversational segments that are invariably present in doctor-patient consultations: problem presentation, physician elicitation, initial formulation, and offer of treatment. This phase of the analysis was conducted using standard qualitative analysis methods. A coding scheme was developed and tested in an iterative fashion by members of the research team. Discrepancies were resolved through discussion and amendment of the coding categories, followed by reapplication of the coding scheme. Once the scheme was judged to be adequate, data were entered into NVivo, a qualitative data-analysis program that facilitates the organisation and retrieval of thematic data. The dataset was then coded by two of the researchers.

The second step involved a narrative analysis of the patient's problem presentation. The goal of the narrative analysis, in keeping with the overall focus on interactional strategies, was to understand the ways in which the patient structured the problem presentation in order to achieve specific social and pragmatic goals. The theories of Labov were used to develop a narrative approach to the analysis of problem presentations. According to Labov, a major social purpose of any narrative is to justify itself - to justify 'holding the stage'. ${ }^{27}$ Central to Labov's theory is his notion of the 'most reportable event'. The 'most reportable event' constitutes the 'so what?' of any narrative - the event that justifies the story. 27,28 It has several characteristics: anomaly, salience, and (often) moral implications. An appropriate 'most reportable event' generates a response from the listener. Using Labov's model, the study sought to understand how patients communicated the 'so what' of their depressive experience - with the goal of understanding how these narratives shaped specific responses in the listening physician. ${ }^{27}$

\section{RESULTS}

\section{The sample}

Table 1 describes the patients and consultations. Outcomes of the consultations varied. About half of consultations $(n=16)$ included an offer of medication by the physician. Patient requests for medication were rare $(n=3)$.

In the following section, the different components of the doctor-patient conversation about depression are discussed.

\section{Problem presentation}

Problem presentation was examined firs to understand the cues patients provided regarding the nature of their depression, whether social or biological. It was found that patients rarely provided explicit attributions for their depression. Conceptual models of depression were communicated to physicians through a more subtle cue: the narrative structure of the problem presentation. Using the narrative analysis approach described by Labov, $^{27}$ it was found that problem narratives varied sharply in terms of their 'most reportable event': the 'so what' of each presentation

In 'symptom narratives' $(n=9)$, the 'most reportable event' was the onset of symptoms. Patients recounting symptom narratives almost always received an offer of medication. In 'situation narratives' $(n=$ 11), the most reportable event was the social situation precipitating the symptom. Patients recounting situation narratives were very rarely offered medication. In 'mixed narratives' $(n=10)$, both symptom and social context seemed equally salient. Physicians offered medication to about half of these patients.

Symptom presenters. Symptom presenters were offered medication in eight out of nine cases. Although this group of patients often referred to life problems in discussing their distress and depression, they were much more focused on their symptoms than on their life situations. Symptom presenters presented their distress in overtly medical terms. The sense of depression as a recurring syndrome and a manifestation of underlying pathology was often expressed among symptom presenters, through references to past episodes:

Patient: ' / have a history of depression ... and I think that I've started to feel depressed again quite recently, excuse me l'm sorry (crying).' 
Table 2. Problem presentation type and offers of antidepressants

\begin{tabular}{|c|c|c|c|c|c|}
\hline Narrative type & Number of cases & $\begin{array}{c}\text { Offer of } \\
\text { medication, \% (n) }\end{array}$ & $\begin{array}{l}\text { Patient accepted } \\
\text { medication, } \%(n)\end{array}$ & $\begin{array}{l}\text { Patient requested } \\
\text { medication, } \%(n)\end{array}$ & $\begin{array}{l}\text { Doctor agreed } \\
\text { to request, } \%[n]\end{array}$ \\
\hline Situation & 11 & $18(2)$ & $100(2)$ & 0 & - \\
\hline Symptom & 9 & $88(8)$ & $50(4)$ & 0 & - \\
\hline Mixed & 10 & $60(6)$ & $66(4)$ & 33 (3) & $66(2)$ \\
\hline
\end{tabular}

GP: 'That's all right ... em ...

Patient: 'I've had two serious bouts of it in the last 10 years and I'm really scared that I will go through that again.' (\#22)

Symptom presenters tended to minimise the social context or antecedents of their distress, often suggesting that their symptoms had arisen spontaneously 'come out of nowhere':

GP: 'How are you? Oh (laughs).'

Patient: 'I'm not doing too good. Em ... er basically l've felt ... really depressed again. (Shaky voice) Em ... I'm quite down.

GP: 'Is there a reason for this?' (pause)

Patient: 'I can't really ... point my finger at anything.' (\#19)

Situation presenters. Situation presenters were offered medication two out of eleven times. These presentations differed sharply from 'symptom narratives'. Although situation presenters often described intense distress and suffering, their stories were focused on severe, novel, or deteriorating situations in their lives:

'The last couple of months it just like, it's a lot of overwhelming. I mean, a lot of things have been happening now... my stepson just came out of jail [after] being locked up fourand-a-half years.' (\#01)

Situation presenters emphasised the logical connection between symptoms and social context. Symptoms were presented neither as novel nor as anomalous, but as a natural consequence of social stress:

GP: 'OK, so what's up with you today?'

Patient: 'I'm just very, very depressed, not feeling good .... On the job, I'm being treated indifferent at this point right now. I'll make this quick. I sent them an email. They wanted me to resign ... .' [lengthy narrative follows] (\#08)

Mixed presenters. Mixed presenters were offered medication about half the time (6/10). In these narratives, it was not possible to identify a single 'most reportable event': both the symptom and the situation seemed to play an equal role:

Well, at present I have so many problems that they are swamping me. I'm not doing anything any more, I can't think, I can't function. My eldest daughter has run away.' (\#24)

Table 2 for summarises these results.

\section{Physician elicitation}

Following the patient's initial problem presentation, the physician often elicits information ${ }^{29}$ to make a diagnosis or a decision about treatment. These segments were examined in order to better understand the kinds of information physicians requested in order to inform their decisions. Several types of inquiry are possible. If physicians were guided largely by Diagnostic and Statistical Manual (DSM) of Mental Disorders diagnostic criteria in determining the nature of the presenting problem, as recommended by the guidelines, they would be expected to assess the problem in terms of symptom criteria. Five symptoms, including one of two cardinal symptoms, are required to make a DSM diagnosis of major depression. If, on the other hand, physicians sought to understand whether the depression was social or biological in origin, they might be expected to inquire about the social context or life problems that preceded the onset of depressive symptoms.

Symptom inquiry. It was found that physicians inquired about symptoms about two-thirds of the time $(n=21)$. However, in most cases (16/21), physicians limited their inquiry to three or fewer symptoms from the depression criteria checklist. Neither inquiry about symptoms, nor patients' responses to these inquiries, was associated with subsequent physician behaviour. In other words, consultations in which more symptoms were elicited or described were no more likely than other consultations to result in an offer of medication. 
Situation inquiry. In most consultations (22/30), physicians inquired about the patient's social situation and context. This form of inquiry was not associated with physician decision making.

Clarifying the relationship between situations and symptoms. In some consultations ( $n=$ 5), physician inquiry was directed towards distinguishing between situational and endogenous causes of depression, usually by inquiring about the temporal sequence of symptoms and situations:

GP: 'Well, do you think this - what do you think came first, the difficulty on the job causing your physical symptoms and your depression or do you think you were depressed and not feeling right before? ... (\#08)

GP: 'Is this, is this common for you, these feelings?...'

Patient: "No. No, um, I mean l've had periods in my life where I was, felt down and depressed. Um, I wouldn't say hopeless, but more down and that. Listless ... .

GP: 'So you've had other times and periods that usually you can relate to a specific situation or just sometimes just feel that way?'(\#09)

GP: 'Do you think you're a depressed person? Or, do you think you're in a stressful situation that's making you feel kind of down about yourself?

Patient: 'I guess I feel like, stressed ... I get overwhelmed and then I get depressed. (\#12).

When physicians engaged in this type of information seeking, medication was not prescribed.

\section{Formulation of the problem}

Following the symptom presentation and the physician's elicitation of further detail, is the formulation of the presenting problem, a phase that often includes the preliminary diagnosis. It has been suggested in the literature that a barrier to depression treatment is patient resistance to the diagnosis.11,15 Yet in the present sample, physicians almost always used the label 'depression' in diagnosing the problem. Thus, the use of this label had no relation to whether the physician offered medication.

In five cases, however, physicians sought to distinguish between depression as a "life problem', and depression as 'real depression':
Some people are depressed and they're sad, and they exude sadness. But the feeling I get from you is that you're like really wound up from what's been happening to you.' (\#08)

When physicians formulated the problem in this way, medication was never prescribed.

\section{The offer of treatment}

As noted, doctors were much less likely to offer medication when the patient seemed to indicate a social model of depression. In only a few cases $(n=6)$ did physicians make offers of medication that were refused. In the present sample, offers that were ultimately refused were made in vague or tentative terms, as if to protect the physician or the patient from the embarrassment of a refusal:

GP: 'And now for the depression I think like we were saying, but it's totally up to you, I think therapy and maybe medication might be helpful. I don't know what you're thinking about though.

Patient: 'Well ... I don't think medication will cure that.' (\#04)

By contrast, the 10 offers that were accepted by patients were highly direct:

'This time you need something?' (\#22)

By contrast to direct offers, which were always accepted, there were no cases in which tentative offers of medication were accepted by the patient.

\section{Persuasion}

According to the depression guidelines, patients who meet the symptom and severity criteria for depression should be offered medication. Presumably, physicians should attempt to educate or otherwise persuade patients who refuse their recommendations. In the present study, physicians attempted persuasion in only four consultations:

GP: 'My feelings are ... why we don't start you on an antidepressant.

Patient: 'I don't want to do that.'

GP: 'Why?'

Patient: 'Erm I don't really think that just medicine can cheer you up.

GP: '[l suggest you] read up about the medication and how it treats people. I see patients here, they're using the medication just to increase the serotonin levels which 
for one reason or another aren't as high as they should be. Just replaces the serotonin and then they get better.' (\#14)

Persuasion was not only rare; it was unsuccessful. No cases were found in which patients refusing medication were successfully persuaded to change their minds.

\section{DISCUSSION}

\section{Summary}

The results of this exploratory study suggest that patients preferences and conceptual models of depression treatment play an important role in physician decision making. Indeed, patients 'drive' treatment decisions in consultations about depression. Physicians generally offered medication to patients who presented their depression in symptomatic terms - terms that are largely in keeping with current diagnostic guidelines. Physicians were highly unlikely to offer medication to patients who presented their depression in social and situational terms. Though patient cues regarding their beliefs and preferences were presented in a subtle form, physicians appeared remarkably sensitive to these cues. Offers of medication that were ultimately refused were made in vague and tentative terms, suggesting perhaps that physicians anticipated refusal. In general, physicians made few efforts to 'educate' patients on the biomedical model of depression or persuade them to accept antidepressants as specified by current guidelines.

There are several potential explanations for why primary care physicians in this study relied so heavily on patient preferences in making decisions about depression treatment. One possibility is that physicians believe that attempts to persuade or 'educate' patients to accept a biomedical model of depression are not likely to succeed. As was seen in this study, patients who conceptualise their depression in social terms are unconvinced by efforts to persuade them otherwise:

'Erm, I don't really think that just medicine can cheer you up'.

Another possibility is that physicians themselves believe that depression that is 'social' in origin is unlikely to respond to antidepressant treatment. The study found evidence to support this hypothesis. One piece of evidence was that physicians often seemed to accept patients' social models of depression without any indication of disagreement. There were no cases in the sample in which physicians attempted to 'correct' patients' understanding of their distress. In addition, physicians in several cases themselves elicited information that would help them make a distinction between social and biological depression. In these instances, they sought to assess the temporal sequence of life events and depressive symptoms. As one physician asked:

'Do you think you're a depressed person? Or, do you think you're in a stressful situation that's making you feel kind of down about yourself?'

Yet a third possibility is that many physicians prefer a 'patient-centred approach to managing depressive symptoms. In such an approach, the patient's concepts and preferences play an important role in shaping the treatment plan. Primary care that is person centred and responsive to the goals and preferences of patients is universally recognised as an important value in general practice. In a recent commentary, Olde-Hartman et al identifed the ways in which patient-centred care can conflict with evidence-based approaches to regulating and evaluating primary care. These so-called 'evidencebased' approaches emphasise the importance of diagnosis and logic-based treatment algorithms. The authors emphasise how addressing the patient's agenda in the consultation is an integral key to providing effective care. ${ }^{30}$

Previous studies on patient preferences for depression care suggest that many patients value informal treatment approaches such as listening and support, and believe that these provide genuine healing. ${ }^{31-33}$ Physicians in the present study appeared to be guided by patients' concepts of depression and preferences for treatment. There were few attempts at persuasion. Offers of medication were often made in highly tentative terms that seemed to emphasise the legitimacy of the patient's preferences regarding treatment.

\section{Strengths and limitations}

A strength of this study was its use of realtime interactional data to understand doctor-patient decision making. Examination of actual interactions between doctors and patients brings important insight into the potential factors influencing physician decision making. Interactional data can shed light on participant intentions and motivations that may lie outside of this article on the Discussion Forum http://www.rcgp.org.uk/bjgp-discuss 
awareness and are not accessible through standard self-report methods.

This exploratory study has important limitations. One is that the size of the dataset and the exploratory nature of the study did not permit an analysis of country differences, or of other key contextual factors such as physician variables, practice settings, and patient histories. Future research should focus on the role of these factors in influencing physician decision making. In addition, the use of transcripts did not permit an analysis of non-verbal cues such as body language or tone of voice. These factors too may play an important role in doctor-patient conversations about distress.

\section{Comparison with existing literature}

The depression taxonomy in recent editions of the DSM/ICD (International Classification of Diseases) is premised on a unitary model of depression. Except in the case of bereavement, the DSM category of depression does not distinguish depression subtypes by cause. Yet a dualistic model of depression, distinguishing depression subtypes according to cause, remains common in the population and may account for low rates of pharmacological treatment among some subgroups. ${ }^{34}$ Many primary care patients believe they suffer from a social 'type' of depression and are unwilling to accept medical treatment. ${ }^{31,32,35,36}$ Similarly, many physicians doubt the effectiveness of pharmacological treatment for groups of patients with pressing real-life problems. ${ }^{11,15,37-40}$ The results of this exploratory study of consultation data support the hypothesis that such considerations influence physician decision making in depression treatment. The result may be less guideline-concordant care, but enhanced patient-led decision making. ${ }^{41}$

\section{Implications for research and practice}

Future research on doctor-patient conversations about depression is needed to test the results of this exploratory study. Research should be conducted in the future to confirm the influence of problem narratives on physician decision making about depression found in the present study. More research is also needed on the common-sense algorithms physicians use in treatment decision making.

For example, many physicians seem to assume that depressive symptoms that are rooted in social causes will not respond to antidepressant medications. They avoid attempts to educate or persuade patients to accept a biomedical model of depression and pharmacological treatment presumably because they do not believe these efforts will result in benefits to patients. Such assumptions contradict the basic premises underlying the depression guidelines. Yet, as growing evidence suggests that the benefits of pharmacological treatment are largely derived from suggestion effects, ${ }^{42-44}$ the hypothesis that the patient's model of depression predicts response to treatment is highly plausible. It is also possible that physicians who respond to patient cues by not offering antidepressants reduce the potential for recovery. In either case, physicians' decision-making algorithms deserve testing through further research. 


\section{REFERENCES}

1. Andreasean N. Brave new brain: conquering mental illness in the era of the genome. Oxford: Oxford University Press, 2001.

2. Luhrman TM. Of two minds: an anthropologist looks at American psychiatry. New York: Alfred A Knopf, 2000

3. Anderson IM. Drug treatment of depression: reflections on the evidence. Adv Psychiatr Treat 2003; 9: 11-20.

4. US Preventive Services Task Force. Screening for depression: recommendations and rationale. Ann Intern Med 2002; 136(10): 760-764.

5. Davidson JR. Major depressive disorder treatment guidelines in America and Europe. J Clin Psychiatry 2010; 71(suppl E1): e04

6. Gelenberg AJ. A review of the current guidelines for depression treatment. J Clin Psychiatry 2010; 71(7): e15.

7. Feldman EL, Jaffe A, Galambos N, et al. Clinical practice guidelines on depression: awareness, attitudes, and content knowledge among family physicians in New York. Arch Fam Med 1998; 7(1): 58-62.

8. Gallo JJ, Ryan SD, Ford DE. Attitudes, knowledge, and behavior of family physicians regarding depression in late life. Arch Fam Med 1999; 8(3): 249-256.

9. Banazak DA, Wills C, Collins C. Late-life depression in primary care: where do we go from here? J Am Osteopath Assoc 1998; 98(9): 489-497.

10. Callahan CM, Dittus RS, Tierney WM. Primary care physicians' medical decision making for late-life depression. J Gen Intern Med 1996; 11(4): 218-225

11. Susman JL, Crabtree BF, Essink G. Depression in rural family practice. Easy to recognize, difficult to diagnose. Arch Fam Med 1995; 4(5): 427-431.

12. Tentler A, Silberman J, Paterniti DA, et al. Factors affecting physicians responses to patients' requests for antidepressants: focus group study. J Gen Intern Med 2008; 23(1): 51-57.

13. Peveler $\mathrm{R}$, Kendrick $\mathrm{T}$. Treatment delivery and guidelines in primary care. $\mathrm{Br}$ Med Bull 2001; 57: 193-206.

14. Littlejohns P, Cluzeau F, Bale R, et al. The quantity and quality of clinical practice guidelines for the management of depression in primary care in the UK. Br J Gen Pract 1999; 49(440): 205-210.

15. Nutting PA, Rost K, Dickinson M, et al. Barriers to initiating depression treatment in primary care practice. J Gen Intern Med 2002; 17(2): 103-111.

16. Kadam UT, Croft P, McLeod J, Hutchinson M. A qualitative study of patients views on anxiety and depression. Br J Gen Pract 2001; 51(466): 375-380.

17. Chew-Graham CA, May CR, Perry MS. Qualitative research and the problem of judgement: lessons from interviewing fellow professionals. Fam Pract 2002; 19(3): 285-289.

18. Akintemi OB. Principles of decision making. In: Obsorn L, DeWitt T, First L, Zenel J (eds). Pediatrics. Philadelphia, PA: Elsevier Mosby, 2005; 57-79.

19. Robinson WD, Geske JA, Prest LA, Barnacle R. Depression treatment in primary care. J Am Board Fam Pract 2005; 18(2): 79-86.

20. Robinson JW, Roter DL. Psychosocial problem disclosure by primary care patients. Soc Sci Med 1999; 48(10): 1353-1362.

21. Sleath B, Svarstad B, Roter D. Physician vs patient initiation of psychotropic prescribing in primary care settings: a content analysis of audiotapes. Soc Sci Med 1997; 44(4): 541-548.

22. Feldman MD, Franks $P$. Epstein RM, et al. Do patient requests for antidepressants enhance or hinder physicians' evaluation of depression? A randomized controlled trial. Med Care 2006; 44(12): 1107-1113.

23. Maynard DW, Heritage J. Conversation analysis, doctor-patient interaction and medical communication. Med Educ 2005; 39(4): 428-435.
24. Heritage J, Maynard DW. Problems and prospects in the study of physicianpatient interaction: 30 years of research. Annu Rev Sociol 2006; 32(1): 351-374.

25. Patton MQ. Qualitative evaluation and research methods, 2nd edn. Newbury Park, CA: Sage, 1990.

26. Ring A, Dowrick CF, Humphris GM, et al. The somatising effect of clinical consultation: what patients and doctors say and do not say when patients present medically unexplained physical symptoms. Soc Sci Med 2005; 61(7): 1505-1515.

27. Labov W. Oral narratives of personal experience. In: Hogan P (ed). Cambridge encyclopedia of the language sciences. Cambridge: Cambridge University Press, 2008.

28. Riessman C. Narrative analysis. Newbury Park: Sage Publications, 1993.

29. Perakyla A. Conversation analysis: a new model of research in doctor-patient communication. J R Soc Med 1997; 90(4): 205-208.

30. Olde Hartman $T$, van Ravesteijn $H$, Lucassen $P$, et al. Why the 'reason for encounter' should be incorporated in the analysis of outcome of care. $\mathrm{Br} J \mathrm{Gen}$ Pract 2011; 10.3399/bjgp11X613269.

31. Karasz A, Garcia N, Ferri L. Conceptual models of depression in primary care patients: a comparative study. J Cross Cult Psychol 2009; 40(6): 1041-1059.

32. Karasz A. The development of valid subtypes for depression in primary care settings: a preliminary study using an explanatory model approach. J Nerv Ment Dis 2008; 196(4): 289-296.

33. Karasz A, Watkins L. Conceptual models of treatment in depressed Hispanic patients. Ann Fam Med 2006; 46(6): 527-533.

34. Dowrick C. Beyond depression: a new approach to understanding and management, 2nd edn. Oxford: Oxford University Press, 2009.

35. Givens JL, Datto CJ, Ruckdeschel K, et al. Older patients' aversion to antidepressants. A qualitative study. J Gen Intern Med 2006; 21(2): 146-151.

36. Good MJ, Good BJ, Cleary PD. Do patient attitudes influence physician recognition of psychosocial problems in primary care? J Fam Pract 1987; 25(1): 53-59.

37. Arean PA, Alvidrez J, Feldman M, et al. The role of provider attitudes in prescribing antidepressants to older adults: leverage points for effective provider education. Int J Psychiatry Med 2003; 33(3): 241-256.

38. Johnston O, Kumar S, Kendall K, et al. Qualitative study of depression management in primary care: GP and patient goals, and the value of listening. Br J Gen Pract 2007; 57(544): 872-879.

39. Uncapher $\mathrm{H}$, Arean PA. Physicians are less willing to treat suicidal ideation in older patients. J Am Geriatr Soc 2000; 48(2): 188-192.

40. Department of Health and Human Services. Mental health: a report of the Surgeon General. Rockville, MD: US Department of Health and Human Services, Substance Abuse and Mental Health Services Administration, Center for Mental Health Services, National Institutes of Health, National Institute of Mental Health, 1999

41. Cape J, Geyer C, Barker C, et al. Facilitating understanding of mental health problems in GP consultations: a qualitative study using taped-assisted recall. Br J Gen Pract 2010; 60(580): 837-845.

42. Moncrieff J, Kirsch I. Efficacy of antidepressants in adults. BMJ 2005: 331(7509): 155-157.

43. Moncrieff J. The antidepressant debate. Br J Psychiatry 2002; 180: 193-194.

44. Kirsch I. Antidepressants and the placebo response. Epidemiol Psychiatr Soc 2009; 18(4): 318-322.

45. Brink-Muinen van den A, Dulmen S van, de Haes HCJM, et al. Dutch National Survey in General Practice. Has patients' involvement in the decision-making process changed over time? Health Expectations 2006; 9: 333-342. 


\section{Appendix 1. Datasets used in the study}

The American dataset was collected for a study of patients' conceptual models of depression. Participants in the original study who screened positive for depression on the PHQ-9 (Patient Health Questionnaire) were 'followed' into the consultation room and their conversations with their physicians were recorded. A fuller description of this dataset may be found in reference 31.

The first UK dataset was a set of 420 transcripts of consultations between GPs and patients with at least one medically unexplained symptom. A fuller description of this dataset may be found in reference 26 .

The second UK dataset was from a wider project to describe the management of mental health consultations in UK general practice. With patient and GP consent, and following local ethics committee approval, 506 patient consultations involving 13 GPs based in five diverse practices within London were audiorecorded between May 2004 and February 2005. Practices were selected to be representative of the area; those with a particular interest in mental health were excluded. Consultations were identified as being related to depression on the basis of HAD (Hospital Anxiety and Depression) score or clinician postconsultation judgement.

The Dutch data were derived from the Second Dutch national survey in general practice, performed by NIVEL (Netherlands Institute for Health Services Research) between 2000 and 2001.45 This study was carried out in practices that were representative of Dutch general practice. Neither GPs nor patients were aware of the topics of interest for the researchers. In the parent study, videorecorded consultations of $142 \mathrm{GPs}$ (76.1\% male) and 2784 patients (41.2\% male) were made. The study was carried out according to Dutch privacy legislation. The privacy regulation was approved by the Dutch Data Protection Authority. Patients were asked to give permission to videorecord one consultation with their GP and they were asked asked to sign an informed consent form. Collected data were kept private as per regulations. 